\title{
Animal Distribution Patterns as a Potential Possible Origin of Covid-19 in Semarang City
}

\author{
Dyah Mahendrasari Sukendra $^{1}$, Bambang Wahyono ${ }^{2}$, Fitri Indrawati ${ }^{3}$, Yunita Dyah Puspita \\ Santik $^{4}$, Nur Siyam ${ }^{5}$ \\ \{dyahmahendra@mail.unnes.ac.id¹, bambang.wahyono@mail.unnes.ac.id², findrati@gmail.com\}
}

Semarang State University. F5 Building, 2nd Floor, Semarang City, Central Java Province, Indonesia. 50229 Phone/Fax. +62248508007 $1,2,3$

\begin{abstract}
SARS-CoV-2 coronavirus can be found in humans\&animals. Some strains of CoV are classified as zoonotic. Semarang city is an area with red zone statuse. There have been cases of Covid-19 in animals infected by humans. But no research conducted on animals infected Covid-19 able to transmit back to humans. Variety of species\&distribution of animals that potential infected with Covid-19 must to know. This study aims to determine the distribution of animal species that can be the possible origin of zoonotic Covid-19. A descriptive study with a survey method conducted in Semarang city. Samples are families that have pets/livestock(dogs,cats,birds,cows) or wild animals around shelter, taken cluster random technique sampling. Questionnaire to collect data. Collected data was analyze using SPSS\&Arc.GIS. The most common animal species found:cat (39\%). $10 \%$ of animal owners live close to people under Covid-19 surveillance. 79\% of respondents do not have pets\&far from Covid-19 cases. $65 \%$ cats has without owners radius $10 \mathrm{~m}$ Covid-19 cases had found, then poultry $(9 \%) \&$ bats $(6 \%)$.
\end{abstract}

Keywords: Mapping, Emerging Zoonotic Disease, Personal Hygine, Distance Limitation

\section{Introduction}

Betacoronavirus is a genus of the SARS-CoV-2 or Covid-19 virus and belongs to the SS-RNA virus group. The city of Wuhan in China is where Covid-19 was first discovered. Covid-19 has become a pandemic and more than 70 countries have been infected with Covid-19. Semarang City is one of the areas in Central Java province with the status of a Covid-19 red zone. Corona virus found in various countries, based on information from WHO (2020) comes from natural evolution. Reverse transmission of $\mathrm{Co}-\mathrm{V}$ that occurs to humans, it is important to know and be aware of, can trigger the emergence of a new pandemic because it has the potential to become an emerging zoonotic disease. Knowing the distribution and presence of animals that have the potential to be a transmission source or reservoir for Covid-19 is important. Transmission control efforts can be carried out through identified transmission mechanisms and information regarding the source of virus transmission, can help determine the right steps for preventing transmission to be achieved.

Indonesian citizens infected with Covid-19 as of April 2020 have reached 9,096 cases. Since this case was first announced on March 2, 2020. As many as 214 positive Covid-19 patients have been found within 24 hours, this is due to the relatively fast transmission of cases. The Covid-19 cases has occur Indonesia and infected residents in various provinces also has been 
designated a red zone. Central Java province is known to have high Covid-19 cases with red zones spread over 20 regions, including the city of Semarang. as many as 28,826 cases with the category of people in monitoring of Covid-19 based on data from corona.jatengprov.go.id. As many as 704 positive cases have been found, while the cases of patients under supervision are 1,307 cases.

Coronavirus $(\mathrm{CoV})$ can be found in humans and animals, and some strains of $\mathrm{CoV}$ are classified as zoonotic. CoV that infects humans is different from $\mathrm{CoV}$ in animals. In humans it can cause MERS-CoV and SARS-CoV. In animals, CoV can infect pigs, dogs, cats, cows and chickens. The virus that causes COVID-19 is declared not to be made in a laboratory or intentionally made, this is evident from the genome sequence analysis on SARS-CoV-2 or other similar viruses. The results showed that bats act as a reservoir for CoV. In the body of $\mathrm{CoV}$ bats are able to mutate and recombine, can continue to form new strains and spread $[1],[2],[3]$.

Corona virus infection has become a pandemic and more than 70 countries have contracted this virus. The corona virus that has become an epidemic is known as Covid-19. Covid-19 or SARS-CoV-2 is a betavirus that easily infects mammals. These viruses have evolved and recombined in reservoirs. Bats were originally referred to as the reservoir of this virus. Although it is also possible that there is an intermediate host between bats and humans. Viruses can evolve naturally possible through evolutionary pathways. Although it is difficult to know the original evolutionary pathway for CoV. If the current pathogenic SARS-CoV-2 or Covid-19 infecting humans comes from animals, this could increase the possibility of future outbreaks [4],[5],[6],[7].

citizens' compliance in carrying out health protocols to prevent transmission between humans, as well as preventing transmission from humans to their petssource of data regarding animals potentially infected with Covid-19 or sources of $\mathrm{CoV}$ zoonotc strains, especially regarding the diversity of species and distribution of animals, compliance and management of residents in carrying out health protocols during pandemic for themselves and their pets/livestock. Information on data on various species, distribution, management of individual health protocols and their pets can be used as a reference source to prevent the spread of pandemic agents, especially viral agents that have the potential for emerging zoonotic diseases.

Because cases of Covid-19 have been found in animals infected by humans. Although there has been no research on animals infected with Covid-19 being able to transmit back to humans. Research on transmission between animals is still being carried out. This condition still needs to be aware of the potential for pandemic emerging zoonotic disease. Knowledge about the source of $\mathrm{CoV}$ that can become animals that have the potential to be infected with Covid-19, namely data on the distribution and diversity of animal species. So, it is necessary to be aware of the potential for pandemic emerging zoonotic disease, because the type of virus that causes Covid-19 can still circulate in animal populations, and it is possible to jump to humans as host. There have also been cases of pets (dogs and cats) contracting Covid-19 from owners and tigers in zoos.

Although it is not yet known whether there is a cycle of transmission back to humans, It is important to know and be aware of the possibility of a reverse infection transmission cycle 
from animals to human [5],[7],[8],[9]. The research objective was to identify viral pandemic agents that have potential as emerging zoonotic diseases, through species data and distribution of animals that are potential sources of transmission of $\mathrm{CoV}$.

\section{Method}

This research is a descriptive study with a survey method. The survey conducted is a predictive survey. It aims to determine the potential for emerging zoonotic disease in viralzoonotic $(\mathrm{CoV})$, when viewed from the species-status-distribution-number of animals (domesticated / livestock / wild) around the respondent's residence. The focus of the research in this study was to determine the description of the types, species, status, distribution, number of animals (domesticated / livestock / wild) that could become possible origins of the coronavirus.

The population of this research is all residents who live in 46 sub-districts of the red zone in the city of Semarang. The sample was selected by residents with the status of People Under Monitoring, Patient Under Supervisions, Covid-treated / recovered / deceased with the criteria of having pets / livestock, and wild animals living around the respondent.

The sampling technique in this study used simple random sampling for a sample of each subdistrict in the city of Semarang. Primary data collection is done by conducting interviews and filling out questionnaires. Research instruments: interview guides and questionnaires. Secondary data in the form of data on the number of viral-zoonotic cases obtained from the Agriculture and Livestock Service Office of Semarang City, Semarang City Health Office. The instruments or tools used in this study were interview guides and questionnaires. The data collection phase begins with conducting a survey recording: types, species, status, distribution, number of animals (domesticated / livestock / wild) that can be the possible origins of coronavirus, information on how to keep animals (domesticated / livestock) owned, management of wild animals in around the residence. The data obtained were analyzed statistically univariate-bivariate with SPSS and ArcGis, then presented in the form a possible origin $\mathrm{CoV}$ zoning maps to determine the potential for emerging zoonotic disease pathogen viruses

\section{Result and Discussion}

Corona virus can change hosts from animals to humans. The potential for a pandemic to occur if $\mathrm{CoV}$ can infect from human to human. Although it is difficult to determine the transmission route of $\mathrm{CoV}$ transmission, it is important to know the evolutionary cycle of the virus. It is important to know the possible origin of $\mathrm{CoV}$ because it is related to the mechanism of transmission of $\mathrm{CoV}$, so that proper prevention can be done immediately [7],[10],[11]. Semarang City area is divided into 16 districts. In this study, a survey was conducted on residents who live in 46 red zone sub-districts in the city of Semarang. From a total of 16 subdistricts in Semarang City, there are 3 sub-districts that have health centers (Animal Health Center located in Mijen, Gayamsari, and Gunungpati). 
Characteristics of Animal Potential Possible Origins Coronavirus in Semarang City. The distribution of animals that have the potential as Potential Possible Origins Coronavirus in Semarang City and which are included in the pet group can be seen in Figure 1.

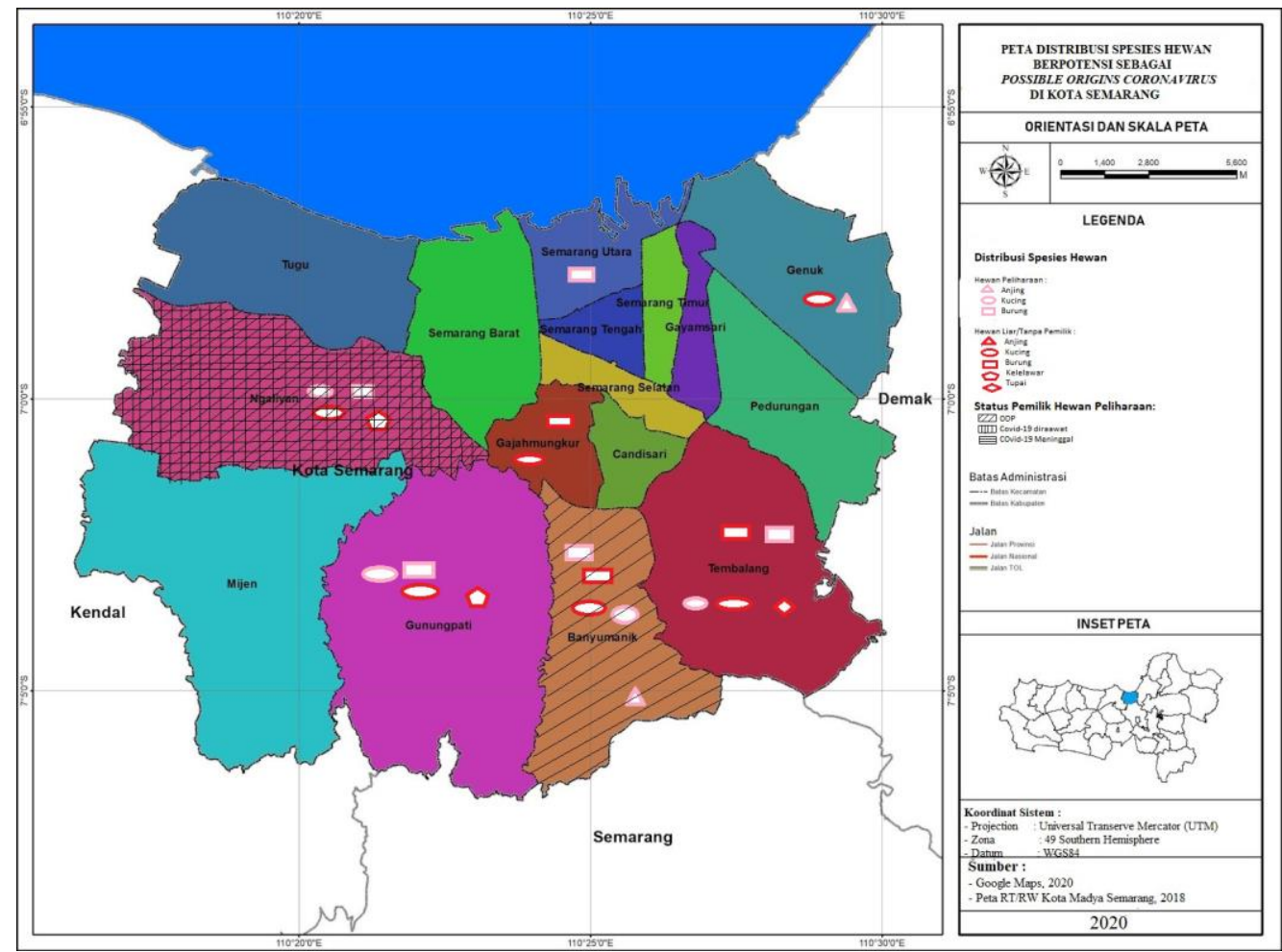

Fig. 1. Distribution Map of Potential Animal Species as Possible Coronavirus in Semarang City

Within a radius of 10 meters, it is known that there are various wild animals that have the potential as possible origins of $\mathrm{CoV}$. The highest number of wild animals found were cats (65\%), $6 \%$ were found bats, $9 \%$ chickens, $16 \%$ birds, and $4 \%$ other types of animals. cats with the highest number of wild animals found, are high-risk animals that are easily infected with $\mathrm{CoV}$ and can change their status as hosts or reservoirs of $\mathrm{CoV}$. This condition is supported by the ability of $\mathrm{CoV}$ to last a long time in the environment, even several hours or days. Even the deployment of Covid-19 can occur through droplets which can contaminate the environment. Animals that have the potential as possible origins of coronavirus, such as dogs, cats, birds, if infected with Covid-19, then transmit Covid-19 to other groups of animals. Can trigger New Emerging Disease (NEDs) in animal groups. Furthermore, if there is transmission back to humans and a cycle occurs, it is estimated that in the future there will be Emerging Zoonotic Disease (EZD) and the potential for a pandemic [11],[12],[13],[14]

In this study, it was found that around $10 \%$ of pets belonged to people who were included in the Covid-19 People Under Monitoring category. Although only a small proportion of animal 
ownership is based on the results of interviews with respondents. The condition is still a concern because of the possibility that pets can contract co-19 from their owners. Especially if pet owners have a history of traveling to the red zone and ignoring the Covid-19 preventive health protocol, when interacting with their pets. Droplets that come from people infected with Covid-19, can survive in the environment for hours or even days. Droplets in the environment and contaminating various equipment and free air, have different time variation ranges [4],[14],[15],[16].

Pet health checks are also important. Sick pets should be examined by a veterinarian. Based on case reports and the results of research conducted by Eric et al. in early 2020 about the symptoms that indicated infected animals corona virus. The specific symptoms that can be found in infected animal Covid of its owner. Showing respiratory symptoms as well as several other symptoms such as diarrhea. With veterinary health checks to vet, a pet can be known possibility of contracting the disease non- $\mathrm{CoV}$ or $\mathrm{CoV}$ by performing rapid test / PCR [4],[9], [17].

Based on the results of the study, there is a possibility that pets contracted Covid-19 from their owners. Transmission from owner to pets, it is very possible. Especially for pets and their owners who live in areas with the red zone category. The latest research and based on a statement from WHO that there is a possibility that the corona virus can be transmitted by air. In this study, only $12 \%$ of animal owners who directly interacted with their pets, after traveling from the red zone, directly interacted with pets without carrying out a health protocol to prevent Covid-19, this made the animals at high risk of contracting Covid-19. Laboratory tests on animals to detect SARS-CoV-2 can be done using a rapid test and Real-Time Polymerase Chain Reaction (RT-PCR). This test is to confirm the possibility of owner-toanimal transmission. Specifically in this study, it was found that only $15 \%$ of pet owners routinely perform pet health checks and $19 \%$ of owners vaccinate their pets. This figure indicates that more than $50 \%$ of the pet population has not been vaccinated. Pets that have not been vaccinated, make pets susceptible to infection. Vaccination in pets, especially vaccines aimed at the prevention of disease transmission with viral agents [10],[12],[13],[17].

Selengkapnya tentang Berdasarkan hasil penelitian, ada kemungkinan hewan peliharaan tertulBased on the survey results, $71 \%$ of the presence of wild / ownerless animals within a $10 \mathrm{~m}$ radius in the People Under Monitoring / Patient Under Supervisions / Covid-treated / Covid-Cured / Covid-died residences was obtained.. There are various frequencies of wild / ownerless animals roaming around the respondent's yard / house. The results showed that $66 \%$ of wild / ownerless animals roam around the respondent's house almost every day, as many as 13 every 5-6 days, while in the range of 1-2 days and 3-4 days there are 3\%, and 16 respondents. stated that no wild / ownerless animal has ever entered the house yard. As many as 25 respondents stated that they interacted directly with wild / ownerless animals and 75\% said they did not. When respondents interacted directly with wild animals / without owners, $6 \%$ of respondents said they used masks and gloves, $10 \%$ used masks but did not wear gloves, $6 \%$ of respondents did not use masks or gloves, $29 \%$ stated that they washed their hands before or after interacting with these animals, 35\% of respondents did wash their hands after interacting with these animals, while as many as $13 \%$ answered other than the procedures that have been mentioned. In this study, bats $(6 \%)$ were also found in the red zone category. Some strains of $\mathrm{CoV}$, which are classified as zoonotic, can infect humans and animals. Pathogenic 
Alphacoronavirus and Bethacoronavirus in mammals. In animals, $\mathrm{CoV}$ can infect dogs and cats. CoV that infects humans and animals, although different, but the results of the study found that bats act as a reservoir of $\mathrm{CoV}$. The $\mathrm{CoV}$ in bats is able to mutate and recombine into new strains, which are able to spread throughout the species. CoV mutated from a reservoir, if it has infected humans, is highly spread and has the potential to become a pandemic [7],[15],[17].Some researchers claim that the SARS-CoV-2 reservoir is a bat, because it is almost like the corona virus that infects bats. Bats can play a role as an intermediate host of $\mathrm{CoV}$ to humans. In another possible evolutionary pathway, nonpathogenic viruses can pass from animals to humans. Then in the human body this virus develops into a pathogenic virus, and then transmission occurs between humans. Rambaut (2020) warns, although it is difficult to know the initial path of the evolution of CoV. If the SARS-CoV-2 pathogen currently infecting humans comes from animals, this could increase the likelihood of future outbreaks. This is because the type of virus that causes Covid-19 can still circulate in animal populations, and it is possible to jump / move host to humans [14], [15], [16].

\section{Conclussion}

The conclusion of this study is that domesticated animals can potentially become hosts for coronavirus, especially when bats are found in residential areas in the red zone.

\section{Acknowledgements}

Acknowledgments are given to the Faculty of Sport Science UNNES who have funded this research, in research funding in 2020. Thanks are also given to Arvia Ditya Maharhani and Anisa Fitri who helped carry out the research and residents of Semarang city and related parties involved in this research.

\section{References}

[1] Wang N, Shi X, Jiang L, Zhang S, Wang D, Tong P, et al. Structure of MERS-CoV spike receptorbinding domain complexed with human receptor DPP4. Cell Respiratory. 2013; 23(8):986.

[2] Kristian GA, Andrew R, Lipkin WI, Edward CH, Robert FG. The proximal origin of SARS-CoV2. Nature Medicine. 2020; DOI: 10.1038/s41591-020-0820-9.

[3] Cui J, Li F, Shi ZL. Origin and evolution of pathogenic coronaviruses. National Rev Microbiology. 2019; 17(3):181-192.

[4] Rahman A, Sarkar A. Risk factors for fatal middle east respiratory syndrome coronavirus infections in Saudi Arabia: analysis of the WHO Line List, 2013-2018.

[5] Phan LT, Nguyen TV, Luong QC, Nguyen HT, Le HQ, et al. Importation and human-to-human transmission of a novel coronavirus in Vietnam. N Engl J Med. 2020.

[6] Li Q, Guan X, Wu P, et al. Early transmission dynamics in Wuhan, China, of novel coronavirusinfected pneumonia. N Engl J Med. 2020; 382:1199-1207.

[7] Zhengli S. and Zhihong H. A review of studies on animaI reservoirs of the SARS coronavirus. PubMed : Virus Research. 2008; 133(1):74-87.

[8] Chen J. Pathogenicity and transmissibility of 2019-nCoVdA quick overview and comparison with other emerging viruses. Microbes Infect. 2020;22(2):69-71.

[9] Lam TT, Jia N, Zhang Y. et al. Identifying SARS-CoV-2-related coronaviruses in Malayan pangolins. Nature. 2020. https://doi.org/10.1038/s41586-020-2169-0 
[10] Nicola MAP. Covid-19 and pets: when pandemic meets panic. Forensic Science International: Reports. 2020; Dec(2):100090. DOI: 10.1016/j.fsir.2020.100090.

[11] Zhou P.A. Pneumonia outbreak associated with a new coronavirus of probable bat origin. Nature. 2020;579(7798):270-273.

[12] Erles K, Toomey C, Brooks HW, Brownlie J. Detection of a group 2 coronavirus in dogs with canine infectious respiratory disease. Virology. 2003;310(2):216-223.

[13] Eric ML, Meriadeg AG, Jeanne BP. The risk of SARS-CoV-2 transmission to pets and other wild and domestic animals strongly mandates a one-health strategy to control the COVID-19 pandemic. One Health. 2020; Apr(13):100133 DOI: 10.1016/j.onehlt.2020.100133.

[14] Wenty DF, Uus S, Ellis DA, Suryo S, Azhari P, Meis JN, et al. Bat Coronavirus of Pteropus alecto from Gorontalo Province, Indonesia. The international journal of tropical veterinary and biomedical research. 2018; 3(2): 36-42. DOI: https://doi.org/10.21157/ijtvbr.v3i2.12359

[15] Li H., Mendelsohn E., Zong C. Human-animal interactions and bat coronavirus spillover potential among rural residents in Southern China. J. Biosaf. Health Educ. 2019;1:84-90. DOI: 10.1016/j.bsheal.2019.10.004.

[16] Lu R., Zhao X., Li J. Genomic characterization and epidemiology of 2019 novel coronavirus: implications for virus origins and receptor binding. Lancet. 2020;395:565-574. DOI: 10.1016/S0140-6736(20)30251-8.

[17] Wertheim JO, Chu DK, Peiris JS, Kosakovsky Pond SL, Poon LL. A case for the ancient origin of coronaviruses. J Gen Virol. 2013;87 (12):7039-45. DOI:10.1128/JVI.0327312. PMC 3676139. PMID 23596293. 